\title{
The TerraSAR-X Ground Segment
}

Stefan Buckreuss, DLR, Microwaves and Radar Institute, Germany Peter Mühlbauer, DLR, German Space Operations Center, Germany Josef Mittermayer, DLR, Microwaves and Radar Institute, Germany Wolfgang Balzer, DLR, Remote Sensing Technology Institute, Germany Rolf Werninghaus, DLR, Space Flight Management, Germany

\begin{abstract}
The Ground Segment of the TerraSAR-X mission provides the infrastructure required to command and control the satellite and the instrument, to receive user requests, to process and archive the acquired data and to deliver the image products. The TerraSAR-X Ground Segment is composed of three major elements designed and operated by DLR,

- $\quad$ the Mission Operations Segment (MOS) provided by the German Space Operation Center (GSOC),

- $\quad$ the Instrument Operation and Calibration Segment (IOCS) provided by the Microwaves and Radar Institute, and

- $\quad$ the Payload Ground Segment (PGS) provided by the German Remote Sensing Data Center and the Remote Sensing Technology Institute

Thus, the Ground Segment represents an interface between the satellite and both the scientific and commercial user services and the users.
\end{abstract}

\section{Introduction}

\subsection{The TerraSAR-X Mission}

TerraSAR-X is Germany's first national remote sensing satellite to be implemented in a public-private partnership between the German Aerospace Center (DLR) and EADS Astrium GmbH, with a significant financial participation from the industrial partner. The radar satellite, which is to be launched in 2006 using a Russian-Ukrainian DNEPR-1 launch vehicle, will supply high-quality radar data for purposes of scientific observation of the Earth for a period of at least five years. At the same time it is designed to satisfy the steadily growing demand of the private sector for remote sensing data in the commercial market [1], [2].

\subsection{Orbit}

For the orbit selection, an altitude of $514 \mathrm{~km}$ has been investigated. The Sun-synchronous dawn-dusk orbit with an 11 day repeat period showed the best performance with respect to order-to-acquisition and revisit times.

\subsection{SAR Instrument}

The TerraSAR-X SAR instrument [3], [4] is an active phased array $\mathrm{X}$-Band system with a centre frequency of $9.65 \mathrm{GHz}$ and a bandwidth of $300 \mathrm{MHz}$.

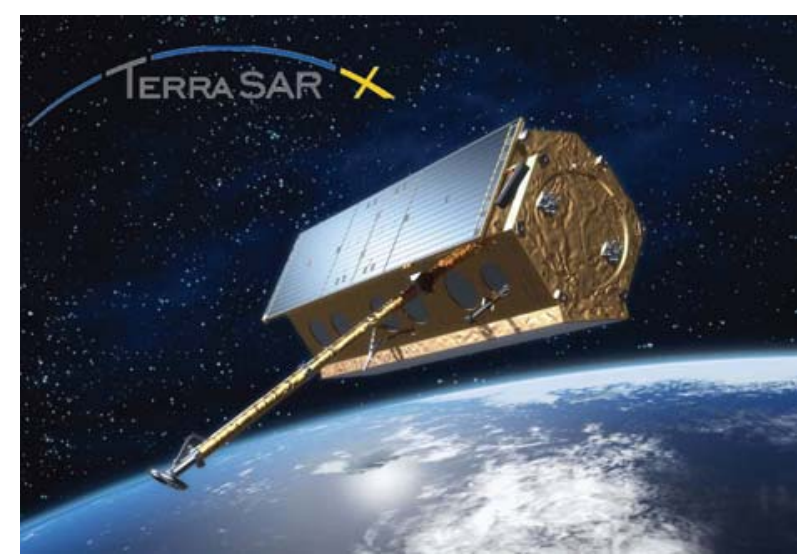

Figure 1 Artist's view of TerraSAR

The antenna is capable of operation in two polarisations, $\mathrm{H}$ and $\mathrm{V}$ and consists of 12 panels with 32 dual polarised, slotted waveguide sub-arrays arranged in elevation each with a dedicated Transmit/Receive Module. The SAR antenna approximate dimensions are $4800 \mathrm{~mm}$ in length, $800 \mathrm{~mm}$ in width and $150 \mathrm{~mm}$ in depth. Beam steering in azimuth $\left( \pm 0,75^{\circ}\right)$ and elevation $\left( \pm 20^{\circ}\right)$ is performed by the Antenna Control Electronics Unit, which provides programmable realtime control of antenna beam shape, pointing and polarisation in transmission and reception.

Generated SAR data are stored in a Solid State Mass Memory Unit of 256 Gbit EOL capacity before they are transmitted to ground via a $300 \mathrm{Mbit} / \mathrm{s} \mathrm{X}$-Band System. 
An internal calibration scheme provides data for onground derivation of replicas for range compression to give high spatial resolution. The internal calibration data also allows for on-ground correction of the raw radar data due to variations in instrument amplitude (i.e. gain) and phase to achieve high radiometric and phase stability.

The SAR instrument is capable of operation in three basic modes:

- Stripmap mode which records an strip of $30 \mathrm{~km}$ width and a maximum length of $1500 \mathrm{~km}$ at a resolution of 3 metres

- ScanSAR mode providing images with an extended swath width of $100 \mathrm{~km}$ and a maximum scene length of $1500 \mathrm{~km}$ at a resolution of 16 metres

- Spotlight mode of imaging an area of 5 up to 10 by $10 \mathrm{~km}$, where a maximum resolution of up to one metre is achieved.

\subsection{Operational Concept}

Once in orbit, the satellite will be operated from the German Space Operation Center (GSOC) in Oberpfaffenhofen. In the system baseline, two ground stations in Germany are foreseen. Weilheim is used as the S-Band telemetry and telecommand station and Neustrelitz serves as the central receiving station for the X-Band downlink. Beyond that, additional Direct Access Stations - commercial partners of Infoterra $\mathrm{GmbH}$ - are foreseen to extend the baseline receiving station concept.

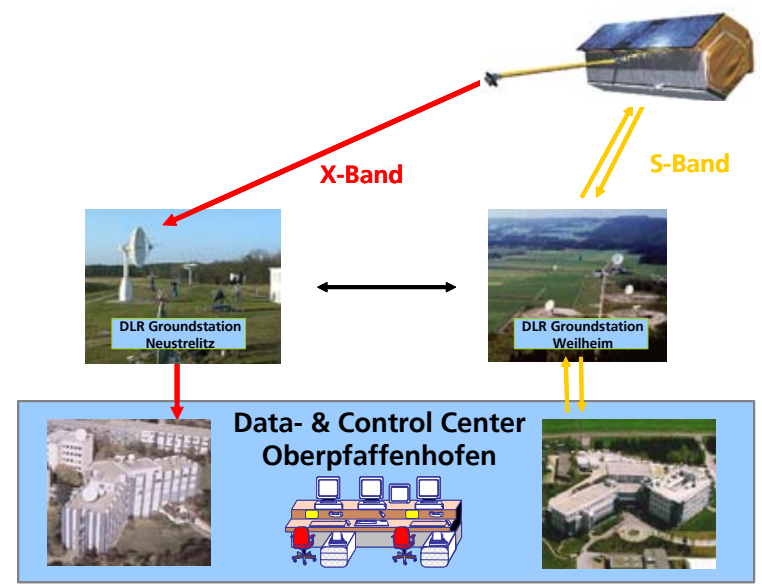

Figure 2 TerraSAR-X Operational Concept

\section{Ground Segment}

\subsection{TerraSAR-X System Context}

The TerraSAR-X Ground Segment is the central facility for controlling and operating the TerraSAR-X satellite, for calibrating the SAR instrument, for archiving the SAR-data as well as generating and distribut- ing the basic data products.

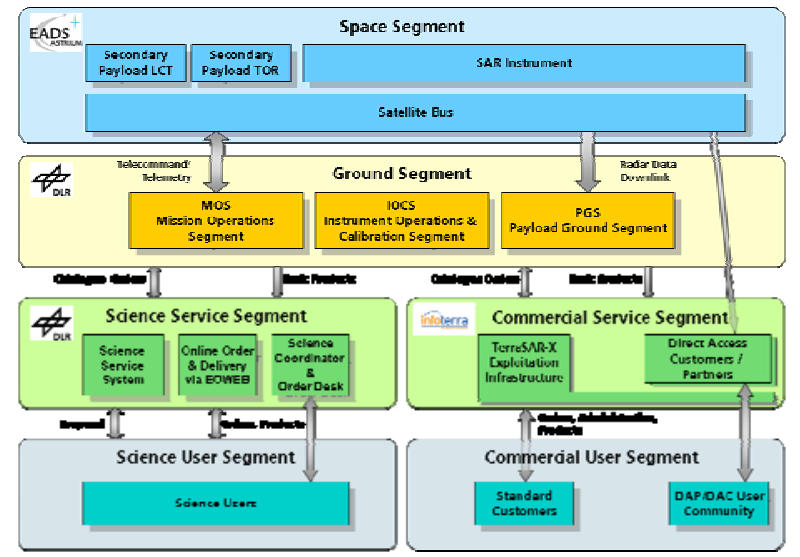

Figure 3 TerraSAR-X System Overview

In the context of the entire TerraSAR-X system, shown in Figure 3, the Ground Segment interfaces with

- the Space Segment, representing the satellite bus, and the SAR instrument provided by EADS Astrium $\mathrm{GmbH}$ as well as the secondary payload,

- $\quad$ the Laser Communication Terminal (LCT), a technology demonstrator for optical data transfer in space designed by TESAT and

- the Tracking, Occultation and Ranging Experiment (TOR), prepared by the Geosciences Research Center in Podsdam (GFZ) in collaboration with the Center for Space Research of the University of Texas (UTCSR),

- the Commercial Service Segment, respectively the TerraSAR-X Exploitation Infrastructure (TSXX), also including Direct Access Stations provided by Infoterra GmbH,

- the Science Service Segment coordinated by DLR and

- the Science- and Commercial User Segment

\subsection{Ground Segment Elements}

The TerraSAR-X Ground Segment is designed and operated entirely by DLR and consists of three major parts:

- the Mission Operations Segment (MOS), provided by the German Space Operations Center (GSOC)

- the Instrument Operations and Calibration Segment, provided by the Microwaves and Radar Institute

- the Payload Operations Segment (PGS), provided by the Remote Sensing Technology Institute in cooperation with the German Remote Sensing Data Center (DFD) 


\subsubsection{Mission Operation Segment (MOS)}

The Mission Operation Segment shall operate from the German Space Operations Center (GSOC) in Oberpfaffenhofen. The neighboring Weilheim ground station shall be used for all routine TT\&C activities. The main functions of the MOS are:

- Provision of S-Band TT\&C ground station networks suitable for the various mission phases: The station in Weilheim is used for routine activities. Additional stations are utilized during LEOP and for contingencies.

- Provision of a Central Checkout System (CCS) for satellite checkout during AIVT: The CCS provides an interface to the satellite or to a simulator during spacecraft AIVT. Development and test platform for various MOS elements (e.g. TM / TC / Display system).

- Satellite Monitoring and Control: Telemetry processing and monitoring, commanding, housekeeping data processing and archiving, data distribution.

- Mission Planning \& Scheduling: Daily planning of space and ground segment activities and generation of command sequences [5].

- Key Management: Generation and distribution of encryption/decryption keys, according to the planned data acquisitions and downlinks.

- Flight Dynamics: Orbit and attitude determination, orbit prediction, maneuver planning.

\subsubsection{Instrument Operations and Calibra- tion Segment (IOCS)}

\subsubsection{Instrument Operations}

The Instrument Operations comprises the following tasks [6], [7]:

- Radar Parameter Generation and Instrument Commanding: Based on user input, the mission planning system generates requests for data takes. Each request will be analyzed and the appropriate sequence of radar parameters expressed as engineering values (PRF, DWP, etc.) will be generated. This sequence will be transformed into macro commands by the command generator and finally transferred into the instrument binary language [8].

- Instrument Monitoring: Housekeeping values which are downlinked via S-Band have to be checked and analyzed both, automatically and manually, to examine instrument health.

- Data Take Verification: The correct execution of the commanded data take is verified via the correlation of the monitored instrument operation with the commanded sequence and an examination whether statistics and prominent radar parameters of acquired data are within margins.

\subsubsection{Calibration Segment}

The calibration relates the SAR image intensity to radar backscattering coefficients and provides informa- tion about the accuracy of this relationship. Estimation and removal of all system-related influences results in pure object signatures. The goal is to model the relationship between geophysical parameters and measured backscattering coefficients. Such quantitative analyses and the development and interpretation of models in different geophysical applications require calibrated data [9].

The overall system calibration includes:

- Compensation/correction of known system errors in amplitude and phase

- Georeferenced transformation of SAR image data to backscatter coefficients within an estimated error

- Internal calibration

- External calibration

- Accomplishment of calibration campaigns

- Development and procurement of calibration targets

- Calibration evaluation

- Delivery of a calibration file for processing to the PGS

As TerraSAR-X will be an operational scientific mission with commercial potential, product quality is of paramount importance. Together with service reliability it will largely decide the success or failure of the mission.

\subsubsection{Payload Ground Segment (PGS)}

\subsubsection{Multi-mission Ground Segment Infra- structure}

The Multi-mission ground segment infrastructure of the German Remote Sensing Data Center consists of

- the $\mathrm{S} / \mathrm{X}$-Band receiving stations in Neustrelitz and

- the distributed Data and Information Management System DIMS composed of systems in Neustrelitz and Oberpfaffenhofen with central User Services located there.

\subsubsection{SAR Processing Suite}

The SAR processing suite consists of three processors:

- the TerraSAR-X Multi-mode SAR Processor TMSP which will be integrated and operated in Neustrelitz to routinely screen all SAR data received in Neustrelitz and to generate L0 products for long-term archiving as well as basic products on request [10],[11]

- the TerraSAR Verification Mode Processor TVSP for software development and maintenance, verification support for all SAR instrument operational modes, the validation and quality assurance of all basic products

- the TerraSAR-X Validation Geocoding Processor TVGP for software development and maintenance, for the validation of geocoded products, and for the precise geocoding of high resolution SAR data for science applications. 


\subsubsection{Data and Information Management System}

The Data and Information Management challenge of the TerraSAR-X scenario is "the satellite in the loop", i.e. a user can order a future product which has to be specified, planned, commanded, acquired, received, processed, archived and delivered. The TerraSAR-X payload ground segment is in charge of the payload data reception, management, processing and the organization of the business process "ordering” including user information services and delivery. Therefore, the data and information management plays a major role in the PGS environment. As a core the Data and Information Management System (DIMS) is used, having interfaces to all other subsystems, the external ground segment components (MOS and IOCS) and the user [12], [13].

\section{References}

[1] Buckreuss, S., Balzer, W., Mühlbauer, P., Werninghaus, R., Pitz, W., The TerraSAR-X Satellite Project, IGARSS 2003, Toulouse, 21.25.07.2003, 2003.

[2] Roth, A.; Eineder, M.; Schättler, B.: TerraSAR$X$ : A New Perspective for Applications Requiring High Resolution Spaceborne SAR Data. In: isprs \& EARSeL, Proc. of the joint isprs 6 earsel workshop \&quot;High Resolution Mapping from Space, Joint isprs and EARSeL Workshop on High Resolution Mapping from Space 2003, Hannover, 6.-8.10.2003

[3] Stangl, Martin; Werninghaus, Rolf; Schweizer, B.; Fischer, C.; Brandfass, Michael; Mittermayer, Josef; Breit, Helko, TerraSAR-X Technologies and First Results., Radar, Sonar \& Navigation, IEE, 2006

[4] Mittermayer J., Alberga V., Buckreuss S., Riegger S., TerraSAR-X: Predicted Performance, Proc. SPIE 2002, Vol. 4881, Agia Pelagia, Crete, Greece, 22 - 27 September 2002.

[5] Wickler, M.; Braun, A.; Geyer, M.: A Strategic Mission Planning Concept for TerraSAR-X. 8th International Symposium on Space Mission Operations and Ground Data Systems, Montreal, 2004.

[6] Mittermayer, J., Schulze, D., Steinbrecher, U., Márquez-Martinez, J., The System Engineering and Calibration Segment of the TerraSAR-X Ground Segment, IGARSS 2005, pp. 4, Seoul, South Korea, 2005.

[7] Mittermayer, Josef; Schulze, Daniel; Steinbrecher, Ulrich; Buckreuss, Stefan (2005): SAR Instrument Operation, Calibration and Verification with a Long Term Data Base. In: DASIA 2005 Conference, S. 4, DASIA 2005 Conference, Edinburgh, 2005
[8] Steinbrecher, Ulrich; Márquez-Martinez, Jose; Mittermayer, Josef; Metzig, Robert; Buckreuss, Stefan; Gottwald, Michael, New Data Take Commanding Concept for TerraSAR-X Instrument. Proceedings EUSAR 2004, Ulm, Germany, ISBN 3-8007-2828-1, 2004

[9] Schwerdt, M., Hounam, D., Bräutigam, B., Alvarez Pérez, J.L., TerraSAR-X: Calibration Concept of a Multiple Mode High Resolution SAR, 25th Anniversary IGARSS 2005, Seoul, Korea, 2005.

[10] Breit, Helko; Börner, Elke; Mittermayer, Josef; Holzner, Jürgen; Eineder, Michael: The TerraSAR-X Multi-Mode SAR Processor - Algorithms and Design, Proceedings EUSAR 2004, pp. 501 - 503, EUSAR 2004, Ulm, May 2004, ISBN 3-8007-2828-1

[11] Eineder, Michael; Helko, Breit; Thomas, Fritz; Birgit, Schättler; Achim, Roth (2005): TerraSAR-X SAR Products and Processing Algorithms, IGARSS IEEE International Geoscience and Remote Sensing Symposium, IGARSS Proceedings, [7], IEEE, pp. 4870 - 4873, IGARSS 2005, Seoul, Korea, 2005

[12] Schättler, Birgit; Wolfmüller, Meinhard; Reissig, Ralf; Damerow, Heiko; Breit, Helko; Diedrich, Erhard: A Description of the Data-Driven SAR Data Workflow in the TerraSAR- $X$ Payload Ground Segment. Proceedings of IGARSS'04, IEEE, Anchorage, Alaska, USA, ISBN 0-78038743-0, 2004.

[13] Mikusch, E.; Wolfmüller, M.; Diedrich, E.; Dietrich, D.; Böttcher, M., Management of "Future Products" in the Distributed Payload Ground Segment for TerraSAR-X., Proceedings of DASIA 2003, Data Systems in Aerospace, Prague, ISBN 92-9092-842-5, 2003 